\title{
A COMPARATIVE ANALYSIS OF FABRICS USED FOR THE GHANAIAN
}

\author{
BASIC SCHOOL UNIFORMS \\ PATIENCE ASIEDUAH DANQUAH \\ University of Cape Coast, Cape Coast, Ghana
}

\begin{abstract}
This study compared three brands of fabrics used for the production of Ghanaian public basic school uniforms based on selected performance characteristics to determine their suitability for the end-use in terms of the properties assessed. The parameters evaluated with the use of experimental procedures included yarn count, weight, colourfastness and shrinkage. The data collected were analysed with the use of the Predictive Analytical Software for windows version 22. Means and standard deviations of the fabric performance characteristics evaluated were calculated. Analysis of Variance at 0.05 alpha level and Pearson Product Moment correlation were also employed. The findings showed significant differences among the investigated fabrics performance characteristics. All the fabrics met the standard specifications for uniform fabrics indicated in the Ghana Standards Authority's specification for uniform fabrics (GS 970, 2009) for the parameters colourfastness, weight and dimensional stability. However, just as these three parameters cannot be used to judge the overall suitability of the fabrics for the end-use. It is therefore recommended that further investigations are carried out on the fabrics to evaluate the other characteristics such as strength and absorbency which could help to establish the better suitability of the investigated fabrics for the end-use (uniforms).
\end{abstract}

KEYWORDS: Fabric Performance Properties, Brands of Fabrics, Ghanaian, Basic School \& Uniforms

Received: Jul 03, 2018; Accepted: Aug 12, 2018; Published: Aug 28, 2018; Paper Id.: IJTFTOCT20183

\section{INTRODUCTION}

Fabrics are the basic raw materials for the manufacture of garments and good quality fabrics are important for garments to function properly to meet their required end-uses (Behera, 2015). Fabrics quality and suitability for an end-use is assessed based on its performance properties such as strength, weight, thickness, elongation, colourfastness, dimensional stability, abrasion resistance, pilling resistance, drape, fabric weave, fibre content and yarn count (Behera, 2015; Chan et al., 2006; Kadolp, 2007; Masteikaitè, Sacevičienè, Apparova, Gerasimovic, 2013; Mehta \& Bhardwaj, 1998; Pizzuto, 2012). The performance properties of fabrics are also influenced by factors such as the kind of raw material used, yarn twist, cover factor, type of dye and fabric construction method (Adetuyi, \&Akinbola, 2009; Pizzuto, 2012; Teli, Khare\&Chakrabarti, 2008). For instance the yarn count of a fabric is noted to determine fabric quality as it is decisive of the weight and strength of a fabric (Kadolph, 2007).

Garments produced from high-quality fabrics for particular end-uses perform satisfactorily during use (Behera\&Hari, 2009; Behera, 1999). However, the various researches conducted on uniforms have indicated poor performance issues which are related to the fabrics used for their production. Kantheti, Devi and Anitha (2015) for instance, in their study on the features preferred in school uniforms by primary school children in Hyderabad (a city in India) found that the children preferred cotton patterned fabric which could absorb sweat while engaged in physical activities. Kantheti et al. (2015) further noted that their school uniforms were durable from one year to 
two years with the majority of the respondents indicating one year. In addition, most mothers indicated that the uniforms faded easily and the parts of the uniform that wore out easily were collars and sleeves. Poor quality fabrics used for the uniform production were indicatedas the factor contributing to the poor durability of uniforms (Kantheti et al., 2015). Kadiadze, in 2014, studied selected Senior High Schools in the Cape Coast Metropolis of Ghana to determine their satisfaction with their school uniforms and found that the students discarded their uniforms early in use due to the poor colourfastness of the fabric.

The poor quality of uniforms experienced might be due to the selection of fabrics of inferior quality not suitable to be used for the production of uniforms. As indicated by Tang and Stylios (2006) the use of an unsuitable or inferior quality fabric for a particular end-use such as school uniform garments fundamentally determines the success or failure of a textile product. Thus, it is very important to assess the quality of a textile fabric to achieve optimum satisfaction in the use of the end product (Luible, Varheemaa, Magnenant-Thalmann, \&Meinander, 2007). The purpose of this study was to compare three brands of fabrics used for public basic school uniforms based on selected performance characteristics to determine their suitability for the end-user in terms of the properties assessed. Three objectives were formulated to guide the study. They were to:

- Determine if differences existed among the three brands of fabrics used for Public Basic school uniform production in terms of weight, yarn count, yarn linear density, colourfastness and shrinkage properties.

- Establish if the performance properties of the three fabrics studied meet the required standard specifications set by the Ghana Standards Authority (GSA) for uniform fabrics

- Determine whether there exist a relationship between yarn count and weight and linear density and weight of the investigated fabrics.

\section{MATERIALS AND METHODS}

\section{Materials}

Three brands of fabrics used for the production of Ghanaian public basic school uniforms were employed for the study. The three different brands of fabrics studied were first labelled A, B and C. In addition, there were two types of each fabric brand that were labelled A1, A2, B1, B2 and C1, C2. A1, B1 and C1 were chocolate 4/saddle brown colours used for skirts, pinafore or a pair of shorts. A2, B2 and C2 were sandy brown colours used for shirts and blouses (Table 1). For the purpose of this study, 1.8 metres of each of the colours of fabrics from the three brands were bought from the market. In all three different chocolate 4/saddle brown and 3 different sandy brown fabrics were obtained making a total of 6 different fabrics which were evaluated. One brand was locally produced (brand A) and the other two were imported (brands B and C). Brand $\mathrm{A}$ was the most expensive among the three fabrics selected followed by brand $\mathrm{B}$ with $\mathrm{C}$ being the least expensive. Table 1 illustrates the quantity of fabrics used for the study. 
Table 1: Fabric Brands and Quantities used for the Study

\begin{tabular}{|c|l|l|c|}
\hline Fabric Samples & \multicolumn{1}{|c|}{ Colour } & \multicolumn{1}{|c|}{ End-use } & $\begin{array}{c}\text { Quantity } \\
\text { (Metres) }\end{array}$ \\
\hline Brand A & Chocolate 4/saddle brown & $\begin{array}{l}\text { Pair of shorts, skirts, Pinafores } \\
\text { Shirts, blouses }\end{array}$ & 1.8 \\
1 & Sandy brown & & 1.8 \\
\hline 2 & & Pair of shorts, skirts, Pinafores & 1.8 \\
\hline Brand B & Shirts, blouses & 1.8 \\
1 & Chocolate 4/saddle brown & 1.8 \\
2 & Sandy brown & Pair of shorts, skirts, Pinafores & 1.8 \\
\hline Brand C & Shocolate 4/saddle brown & Shirts, blouses & $\mathbf{1 0 . 8}$ \\
\hline 1 & Sandy brown &
\end{tabular}

\section{Methods}

Test methods by International Organisation for Standardization (ISO) adopted by GSA were used by the researcher. Before the investigation, the specimens were conditioned for 24 hours in a relaxed state at a relative humidity of $65 \pm 2 \%$ and a temperature of $21^{\circ} \pm 1^{\circ} \mathrm{C}$ as indicated by the ISO 139 (1973). The performance characteristics evaluated on the fabrics were:

\section{Woven Fabric Yarn Count}

Three specimens each measuring $2.5 \mathrm{~cm}$ in the warp direction and $2.5 \mathrm{~cm}$ in the weft direction were cut from each brand of uniform fabric and labelled for easy identification. A magnifying glass used to test for yarn count where the numbers of yarns in the warp and weft directions of the specimens were counted 5 times and each recorded separately. After that an average warp and weft count was calculated for each fabric type.

\section{Weight of Fabrics}

Five specimens each with the area of $0.015 \mathrm{~m}^{2}$ were cut with the help of a sample cutter to form each fabric brand and labelled. Each specimen was weighed using Adams equipment weighing balance, Model No. B215846278. The average weight of the five specimens were calculated and indicated in grams per square meter.

\section{Colourfastness to Washing}

Two specimens $10 \mathrm{~cm} \times 4 \mathrm{~cm}$ were cut from each brand of fabric and labelled. A multi-fibre fabric of same measurement was attached to each specimen. The specimens were then washed with key bar soap using Standard LaunderOmeter (Gyrowash 315) and dried at room temperature after which colourfastness assessment was carried out with the aid of the ISO Grey Scale for colour change. To assess fastness to staining, the ISO grey scale for staining was used. Five readings were recorded in the visual inspection of the specimens for colour change and staining for each fabric in a welllighted colour assessment chamber. The grey scale ratings ranged from excellent to poor with grade 5 being excellent, 4 very good, 3 good, 2 moderate and 1 poor colourfastness.

\section{Dimensional Stability (Shrinkage) to Washing}

Two specimens measuring $15 \mathrm{~cm} \times 15 \mathrm{~cm}$ were cut from each fabric such that the yarns in both directions (warp and weft) were parallel to the edges and labelled for easy identification. Two lines of $10 \mathrm{~cm}$ apart and $2.5 \mathrm{~cm}$ from the specimen edges were marked on each specimen. The specimens were washed with Standard Launder-Ometer (Gyrowash 315) and 
dried at room temperature. After that, the distance between the marked lines $(10 \mathrm{~cm} \times 10 \mathrm{~cm})$ were re-measured from each direction (warp and weft) of the specimen with the aid of tape measure and recorded to determine if any change in the original length $(10 \mathrm{~cm} \times 10 \mathrm{~cm})$ occurred. Percentage dimensional change (shrinkage) was calculated with the formula provided by GS, ISO 5077 (1984), which was:

$$
\text { Dimensional Change }=\frac{\text { ChangeinLength }}{\text { Original Length }} \times 100
$$

\section{Yarn Linear Density of Fabrics}

Seven rectangular specimens ( 2 for warp, 5 for weft) measuring $50 \mathrm{~cm} \times 2.5 \mathrm{~cm}$ were cut from each fabric and labelled. From the 7 specimens, 350 (100 for warp and 250 for weft) strands of threads were removed. The 100 strands representing warp threads were weighed together using Adams equipment weighing balance, Model No. B215846278. The 250 weft threads were also weighed in a group of 50 . Linear density was calculated with the formula provided by 1 SO $7211 / 5$ (1984) as:

$$
\text { Linear density in tex units }=\quad \frac{\text { Mass of threads taken from fabric in grams }}{\text { Total length of threads in meters }} \times 100
$$

Where total length $=$ mean straightened length $\times$ number of threads weighed.

\section{Data Analysis}

Data for the study was analysed by the use of the Predictive Analytical Software (SPSS) for Windows version 22. Means and standard deviations of the fabric performance characteristics such as yarn count, weight and yarn linear density were calculated and presented. Analysis of Variance at 0.05 alpha level and Pearson Product Moment correlation were also employed.

To determine whether the performance properties of the fabrics investigated meet the standard requirements, the fabric performance characteristics had to be compared to the specifications indicated in GS 970 (2009) (Textilesspecification for fabrics for shirts and uniforms). Table 2 provides the standard specifications with which the test results for the parameters studied were compared. A fabric that meets all the standard requirements stated in Table 2 is suitable to be used for school uniform (GS 970, 2009). In the standard GS 970 (2009), letters of the alphabets are used to represent the fibre content of fabrics. They are:

- C stands for $100 \%$ cellulose.

- $\quad \mathrm{CR}$ is for a cellulose fibre and synthetic fibre blend containing more than $50 \%$ cellulose fibre.

- $\mathrm{SR}$ is for a cellulosic fibre and synthetic fibre blend fabric containing less than $50 \%$ cellulosic fibre.

Based on the assessment made on the three fabric brands, their fibre content placed them under the SR. For that reason, the parameter values presented in theTable 2 cover fabrics that fall under the SR. 
Table 2: Standard Specifications for Parameters Indicated in GS 970:2009

(Textile Specification for Shirts and Uniform Fabrics)

\begin{tabular}{|c|c|c|c|c|c|c|}
\hline \multirow{3}{*}{ Type of Fibre } & \multirow{3}{*}{$\begin{array}{c}\text { Mass per Unit Area } \\
\qquad\left(\mathrm{g} / \mathrm{m}^{2}\right)\end{array}$} & \multicolumn{4}{|c|}{ Colourfastness to Washing } & \multirow{3}{*}{$\begin{array}{c}\text { Dimensional Change } \\
\text { on Washing } \\
\text { (Shrinkage) }(\%) \text { Max }\end{array}$} \\
\hline & & \multirow{2}{*}{$\begin{array}{l}\text { Colour } \\
\text { Change }\end{array}$} & \multicolumn{3}{|c|}{ Staining of } & \\
\hline & & & Cotton & Polyester & Polyamide & \\
\hline $\begin{array}{l}\text { SR } \\
\text { (Fabric blend } \\
\text { containing less } \\
\text { than } 50 \% \\
\text { cellulose fibre ) }\end{array}$ & $\begin{array}{c}>280 \\
235-279 \\
190-234 \\
140-189 \\
<140\end{array}$ & 4 & $3-4$ & 3 & - & 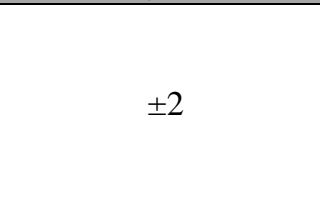 \\
\hline
\end{tabular}

Table 2 shows that the mass per unit area (weight) of a suitable fabric for uniform fabric could be greater than $280 \mathrm{~g} / \mathrm{m}^{2}$ and less than $140 \mathrm{~g} / \mathrm{m}^{2}$.In terms of colourfastness to washing (colour change) a suitable uniform fabric should have a grey scale value of 4 . For staining, the grey scale reading for cotton should be 3-4, 3 for polyester and no value was indicated for polyamide. The percentage dimensional stability value of a suitable uniform fabric is $\pm 2 \%$ maximum.

\section{RESULTSAND DISCUSSIONS}

Table 3 presents the results for the performance properties of the fabrics investigated.

\section{Weave Type, Yarn Count, Yarn Linear Density and Weight of the Fabrics}

All the fabrics studied were plain weave of $1 \times 1$ repeat in both warp and weft directions. With regard to yarn count, the warp directions of the fabrics had a higher number of yarns per inch than the weft (Table 3). Table 3shows that fabric $\mathrm{C} 1$ had the highest number of yarns in the warp direction $(\mathrm{M}=81)$, followed by $\mathrm{C} 2(\mathrm{M}=79)$ and $\mathrm{A} 1(\mathrm{M}=56)$ had the lowest number of yarns. In the weft direction, fabric $\mathrm{C} 1$ had the highest count $(\mathrm{M}=68)$ and fabrics B1 and B2 had the least numbers of yarns. The variations noted in the fabrics yarn count could contribute to differences in the weight of the fabrics. For yarn linear density, in both the warp and weft directions, fabrics A1 and A2 had the highest mean value of yarn linear density with $\mathrm{C} 1$ obtaining the lowest mean linear density values (warp= 41 , weft $=18$ ). The differences in the linear density of the fabrics could also contribute to disparities in the weight of the fabrics.

Differences were observed from Table 3 with regard to the fabric weight where fabric A2 had the highest weight $\left(M=175 \mathrm{~g} / \mathrm{m}^{2}\right)$ followed by $\mathrm{A} 1\left(\mathrm{M}=174 \mathrm{~g} / \mathrm{m}^{2}\right)$ and $\mathrm{C} 2$ had the lowest weight $\left(\mathrm{M}=107 \mathrm{~g} / \mathrm{m}^{2}\right)$. This finding could be attributed to the different fibre contents, number of yarns in the warp and weft directions and their yarn linear densities. Pizzuto (2012) and Glock and Kunz (2005) indicated that fabric weights vary due to differences in fibre content, number of yarns per $2.5 \mathrm{~cm}(1 \mathrm{inch})$ as well as in yarn size.

The weights of fabrics B1, B2 and C1 however, fell within the range provided by Pizzuto (2012) for medium weight fabrics which is $120-170 \mathrm{~g} / \mathrm{m}^{2}$, making the fabrics of medium weight. The weights of fabrics A1 and A2 rather fell a little above the higher limit for medium weights and that of C2 fell below the lower limit for medium weight fabrics and that of $\mathrm{C} 2$ below the lower limit for medium weight cloth. Fabrics A1 and A2 are not heavy weight fabrics as their weights are closer to medium than heavy weight ones. Likewise, the weight of $\mathrm{C} 1$ is nearer to medium than light weight fabrics. From the results, it can therefore be concluded that all the fabrics used for the study were medium weight and met the standard required for weight indicated in the GS 970 (2009). 
Table 3: Results for the Performance Properties of the Fabrics Studied

\begin{tabular}{|c|c|c|c|c|c|c|c|c|c|c|c|c|}
\hline \multirow{3}{*}{$\begin{array}{l}\text { Fabric } \\
\text { Brands }\end{array}$} & \multirow{3}{*}{ Fibre Content } & \multirow{3}{*}{$\begin{array}{c}\text { Mean } \\
\text { Weight } \\
\left(\mathrm{g} / \mathrm{m}^{2}\right)\end{array}$} & \multicolumn{4}{|c|}{ Colourfastness to Washing (Grey Scale) } & \multicolumn{2}{|c|}{$\begin{array}{c}\text { Mean } \\
\text { Shrinkage } \\
(\%)\end{array}$} & \multicolumn{2}{|c|}{$\begin{array}{l}\text { Mean Yarn } \\
\text { Count }\end{array}$} & \multicolumn{2}{|c|}{$\begin{array}{c}\text { Mean Yarn } \\
\text { Linear } \\
\text { Density (Tex) }\end{array}$} \\
\hline & & & \multirow{2}{*}{$\begin{array}{l}\text { Change } \\
\text { in Colour }\end{array}$} & \multicolumn{3}{|c|}{ Staining } & \multirow{2}{*}{ Warp } & \multirow{2}{*}{ Weft } & \multirow{2}{*}{ Warp } & \multirow{2}{*}{ Weft } & \multirow{2}{*}{ Warp } & \multirow{2}{*}{ Weft } \\
\hline & & & & Cotton & Polyester & Polyamide & & & & & & \\
\hline A1 & $\begin{array}{l}35 \text { viscose } \\
65 \text { polyester }\end{array}$ & 174 & 5 & $4-5$ & 5 & $4-5$ & 2 & 1 & 56 & 50 & 82 & 46 \\
\hline A2 & $\begin{array}{l}35 \text { viscose } \\
65 \text { polyester }\end{array}$ & 175 & 5 & $4-5$ & $4-5$ & $4-5$ & 2 & 2 & 57 & 52 & 84 & 45 \\
\hline B1 & $\begin{array}{c}11 \text { cotton } \\
89 \text { polyester }\end{array}$ & $13 \beta$ & $4-5$ & 4 & 4 & $4-5$ & 1 & 2 & 61 & 45 & 79 & 45 \\
\hline B2 & $\begin{array}{c}21 \text { cotton } \\
79 \text { polyester }\end{array}$ & 138 & 5 & 4 & 5 & $4-5$ & 2 & 2 & 62 & 46 & 78 & 43 \\
\hline $\mathrm{C} 1$ & $\begin{array}{c}1 \text { cotton } \\
99 \text { polyester }\end{array}$ & 121 & 5 & $4-5$ & 4 & $3-4$ & 2 & 1 & 81 & 68 & 41 & 18 \\
\hline $\mathrm{C} 2$ & $\begin{array}{l}2 \text { cotton } \\
98 \text { polyester }\end{array}$ & 107 & 5 & $4-5$ & 4 & 3 & 2 & 2 & 79 & 66 & 42 & 19 \\
\hline
\end{tabular}

A1, B1, C1= the Chocolate 4/saddle brown colours of fabric brands A, B and C, A2, B2, C2=the sandy brown colours of fabric brands A, B and C

\section{Colourfastness to Washing of the Fabrics}

As regards colourfastness to washing, from the Table 3, it is evident that all the fabrics performed excellently with colour change except B1 which obtained a value between very good and excellent. For colour to staining on cotton, fabrics A1, A2, C1 and C2 had a grey scale rating between very good and excellent with B1 and B2 attaining a very good rating. For staining on polyester, fabrics A1 and B2 had a grey scale rating of excellent while B1, C1 and C2 obtained a rating of very good and A2 had a grey scale rating between very good and excellent (Table 3 ). With regard to staining on nylon, it is observed from Table 3 that while fabrics A1, A2, B1 and B2 showed an intermediate rating between very good and excellent, fabric $\mathrm{C} 2$ had the best rating and $\mathrm{C} 1$ had an intermediate rating of good and very good. From the results on colour fastness (colour change and staining) it can be deduced that all the uniform fabrics used for the study have good colourfastness to washing and will perform satisfactorily or maintain their colour during use as school uniforms. The colour of the fabrics is not likely to affect other clothing items worn on the body or during washing. Textile Machinery Network (2013) stated that poor colourfastness in garment such as school uniforms can affect other clothing items worn or during washing by destroying the items appearance and wear ability. It must however be stated that all the fabrics had good colourfastness and obtained grey scale values greater than the values indicated in GS 970 (2009). This might be due to the use of good quality dyes by the manufacturers of all the fabrics investigated. The finding from this study is similar to Ünal et al. (2011).Ünal et al. (2011) found in a study on the analysis and improvement of trouser fabrics for primary school uniforms that colour change values for all the fabrics they investigated were acceptable.However, it is observed that the GS 970 (2009) did not indicate any grey scale value for wool, and the polyamides, so no comparison could be made.

\section{Dimensional Stability to Washing of the Fabrics}

With regard to dimensional stability (shrinkage), the results presented in Table 3 show good dimensional stability for all the fabrics indicating that the fabrics have potential to retain their original shape and remain stable during use and care, making them suitable for the end-use. The finding of this study regarding dimensional stability may be as a result of the fibre content of the fabrics, the fabrics being tightly woven and their yarn count. For instance, Pizzuto (2012) stated that a higher thread count means that more threads are fitted within the fabric and this can reduce fabric shrinkage as the yarns will not have much room to shift. For the fibre contents of the fabrics studied, they all contained higher amounts of polyester which is a hydrophobic fibre. According to Pizzuto (2012), hydrophobic fibers such as polyester shrink less when 
washed than hydrophilic fibers. The reason given to this was that, fibre swelling which is one of the causes of shrinkage occurs very little in hydrophobic fibers. In addition, all the fabrics obtained shrinkage values both in the warp and weft directions that met the standard in GS 970 (2009).

\section{Analysis of Variance Results for the Comparison of the Performance Characteristics of the Investigated Fabrics}

The analysis of variance results in Table 4 shows significant differences among the weights, shrinkage and yarn counts of the fabrics with their p-values as 0.001. For the weight and yarn count of the fabrics, Post Hoc analysis to determine between group variance revealed that the differences were significant between all groups. However, in terms of dimensional stability, the Post Hoc analysis of the data to establish between group differences showed that in the warp direction, differences were significant between fabrics $\mathrm{A} 2 \times \mathrm{A} 1, \mathrm{~A} 2 \times \mathrm{B} 2, \mathrm{~A} 2 \times \mathrm{C} 1, \mathrm{~A} 2 \times \mathrm{C} 2, \mathrm{~B} 1 \times \mathrm{B} 2$ and $\mathrm{B} 1 \times \mathrm{C} 2$ while in the weft direction, differences were noted between fabrics $\mathrm{A} 1 \times \mathrm{B} 1, \mathrm{~A} 1 \times \mathrm{B} 2, \mathrm{~A} 1 \times \mathrm{C} 1, \mathrm{~A} 1 \times \mathrm{C} 2, \mathrm{~A} 2 \times \mathrm{B} 1, \mathrm{~A} 2 \times \mathrm{B} 2, \mathrm{~A} 2 \times \mathrm{C} 1$ and $\mathrm{A} 2 \times \mathrm{C} 2$.

The significant differences found among the weights of the fabrics investigated might be due to the disparity in the fabric, fibre contents, yarn counts as well as their yarn linear densities as observed in Table 3. For dimensional stability (shrinkage), although, significant differences existed among the fabrics studied, they all met the standard requirements indicated in GS 970 (2009). This indicates that all the fabrics studied will do well during use with regard to dimensional stability. With regard to the yarn counts of the fabrics, Table 3 illustrates that even within the same brand there existed slight differences in yarn counts of the fabrics in both warp and weft directions. The results of yarn count is consistent with Ünal et al. (2011) who also found differences in the yarn counts of the trouser fabrics used for primary school uniforms they investigated.

Table 4: ANOVA Results for Differences among Fabric Brands and their Weights, Strengths, Elongations, Shrinkage and Yarn Counts

\begin{tabular}{|c|c|c|c|c|c|c|c|c|c|c|c|c|c|c|c|c|c|}
\hline \multirow{2}{*}{ Parameter } & \multirow[t]{2}{*}{ Fabric Brands } & \multicolumn{2}{|c|}{$\mathrm{A} 1$} & \multicolumn{2}{|c|}{$\mathrm{A} 2$} & \multicolumn{2}{|c|}{ B1 } & \multicolumn{2}{|c|}{ B2 } & \multicolumn{2}{|c|}{$\mathrm{C} 1$} & \multicolumn{2}{|c|}{$\mathrm{C} 2$} & \multirow{2}{*}{ MS } & \multirow{2}{*}{ df } & \multirow{2}{*}{$F$} & \multirow{2}{*}{ p-value } \\
\hline & & $\mathrm{M}$ & SD & M & SD & $\mathrm{M}$ & SD & M & SD & M & SD & M & SD & & & & \\
\hline Weight $\left(\mathrm{g} / \mathrm{m}^{2}\right)$ & & 172 & 2.099 & 174 & 1.488 & 138 & 0.948 & 139 & 0.667 & 121 & 1.315 & 107 & 2.276 & 14387.79 & 5 & 5803.37 & $0.001^{*}$ \\
\hline $\begin{array}{c}\text { Shrinkage }(\%) \\
\text { Warp }\end{array}$ & & 1 & 0.883 & 2 & 0.458 & 2 & 0.593 & 0.8 & 0.561 & 1 & 0.915 & 1 & 1.069 & 4.933 & 5 & 8.136 & $0.001^{*}$ \\
\hline Weft & & 2 & 0.834 & 2 & 0.507 & 1 & 0.817 & 1 & 0.724 & 2 & 0.915 & 1 & 0.594 & 5.324 & 5 & 9.584 & $0.001^{*}$ \\
\hline $\begin{array}{l}\text { Yarn count } \\
\text { Warp } \\
\text { Weft }\end{array}$ & & $\begin{array}{l}56 \\
50\end{array}$ & $\begin{array}{l}4.147 \\
2.864\end{array}$ & $\begin{array}{l}58 \\
52\end{array}$ & $\begin{array}{l}2.775 \\
2.302\end{array}$ & $\begin{array}{l}62 \\
45\end{array}$ & $\begin{array}{l}1.140 \\
0.894\end{array}$ & $\begin{array}{l}62 \\
46\end{array}$ & $\begin{array}{l}0.894 \\
1.789\end{array}$ & $\begin{array}{l}82 \\
69\end{array}$ & $\begin{array}{l}2.387 \\
2.608\end{array}$ & $\begin{array}{l}80 \\
67\end{array}$ & $\begin{array}{l}1.483 \\
3.131\end{array}$ & $\begin{array}{l}633.520 \\
542.593\end{array}$ & 5 & $\begin{array}{l}108.915 \\
95.471\end{array}$ & $\begin{array}{l}0.001^{*} \\
0.001^{*}\end{array}$ \\
\hline
\end{tabular}

*Significantp $<0.05, M=$ Mean, $S D=$ Standard Deviation,,$M S=$ Mean Square

\section{Relationship between Yarn Count and Weight and Linear Density and Weights of Investigated Fabrics}

To ascertain whether significant relationships existed between yarn count and weight and linear density and weights of the investigated fabrics, correlation analysis was employed. The result is provided in Table 5. 
Table 5: Correlation Results for Yarn Count and Weight and Linear Density and Weights of Investigated Fabrics

\begin{tabular}{|l|c|c|c|c|}
\hline $\begin{array}{c}\text { Variables } \\
\text { Compared }\end{array}$ & $\begin{array}{c}\text { Yarn Count } \\
\text { Warp vs. } \\
\text { Weight }\end{array}$ & $\begin{array}{c}\text { Yarn Count } \\
\text { Weft vs. } \\
\text { Weight }\end{array}$ & $\begin{array}{c}\text { Linear Density } \\
\text { Warp vs. } \\
\text { Weight }\end{array}$ & $\begin{array}{c}\text { Linear } \\
\text { Density Weft } \\
\text { vs. Weight }\end{array}$ \\
\hline $\begin{array}{l}\text { Pearson } \\
\begin{array}{l}\text { Correlation } \\
\text { (r) }\end{array}\end{array}$ & $-0.857 * *$ & $-0.599 * *$ & $0.839 * *$ & $0.819 * *$ \\
\hline$P$-value & 0.001 & 0.001 & 0.001 & 0.001 \\
\hline
\end{tabular}

Significant $* * \mathrm{p}<0.01$

According to the results obtained from the correlation analysis performed to evaluate the relationship between yarn count and weightand linear density and weights of the investigated fabrics, the relationship between the parameters were statistically significant (Table 5). From Table 5, it can be noted that there was a positive relationship between the parameters yarn linear density and weight both in the warp $(r=0.839, p<0.01)$ and weft $(r=0.819, p<0.01)$ directions. On the other hand, a negative relationship was established between yarn count and weight of the fabrics studied (Table 5). The negative relationship between the two parameters, indicates that as the fabrics yarn count increases the weight decreases (Table 5). The negative relationship observed between yarn count and weight in this current study is obvious from the mean yarn count values in Table 3. As noted in Table 3, the brand $\mathrm{C}$ for example had high yarn count values both in the warp and weft, but attained lower weight values.The finding is contrary to what Pizzuto (2012) indicated that usually the higher the fabric count, the better the quality of the fabric in terms of weight. The outcome is also dissimilar to what Ünal et al. (2011) found that the fabric with the highest weight also had high warp and weft counts. The results from this study regarding yarn count and weight show that the yarn count alone cannot be used to determine the weight of fabrics, but other parameters such as yarn linear density together with yarn count influence fabric weight. The brand $\mathrm{C}$ fabric, forexample, is high on yarn count, but low in linear density, which could be a reason for its low weight.

On the other hand, the positive correlation observed between yarn linear density and weight in this current study is in agreement with what Saiman et al. (2014) found. They explained that higher linear densities result due to higher fibre loading in the yarns; in effect influencing weight and strength of the fabrics. It is noted in this study that the fabrics with high linear densities had equally high weight values as seen in Table 3.

\section{Suggested Additions to the GS 970:2009 (Standard Specification for Uniform Fabrics)}

The researcher noted that certain parameters that could also help in deciding suitability of fabrics for uniforms were not indicated in the GS 970 (2009). The parameters are yarn count and yarn linear density. They are discussed in the sub-headings that follows;

\section{Yarn Count Properties of Fabrics}

The yarn count is one parameter that is indicative of quality in fabrics (Pizzuto, 2012). Pizzuto (2012) stated that in most end uses where durability is important such as in children's wear, uniforms and active sportswear, higher ends and picks per inch are preferable to lower counts. This shows that since durability is paramount in uniform fabrics there is the need to provide acceptable numbers of ends and picks per inch at which uniform fabrics can perform satisfactorily. That will aid manufacturers to follow suit and come up with a variety of fabrics that can be used for such products. Perhaps if another set of standards for various end-uses are studied and additional analysis carried out on other fabrics in addition to what has been done in this current study, an estimate of the number of ends and picks per inch can be established for 
uniform fabrics.

\section{Yarn Linear Density Properties of Fabrics}

With regard to yarn linear density, it is established from literature and this current study, that it influences a number of fabric performance properties such as weight. For instance, Saiman et al. (2014) observed that the mechanical properties such as strength, increased when yarn linear density increased. As evident from this current study, the brand C had the highest number of ends and picks per inch yet attained the least weight value (Table 3). This can be attributed to its fibre type and the linear density as it had the lowest linear density values both in the warp and weft directions.The finding shows that yarn count alone cannot be used to judge the quality of a fabric especially in terms of weight, but other attributes such as fibre type and linear density must be taken into consideration. There is therefore the need for linear density to be included in the standard specification with the appropriate values for warp and weft directions.

\section{CONCLUSIONS}

From the results obtained from the study, a number of conclusions can be drawn. It can be concluded that significant differences existed among the fabrics in terms of the performance characteristics analysed.However, all the fabrics met the standard specifications for uniform fabrics indicated in the Ghana Standards Authority's specification for uniform fabrics (GS 970, 2009) for the parameters colourfastness, weight and dimensional stability making it difficult to state exactly which fabric brand is most suited for the end-use. As it is, all the uniform fabrics analysed would perform satisfactorily during use in terms of colourfastness, weight and dimensional stability. One would therefore be tempted to conclude that all the fabrics investigated are suitable for uniforms in Ghana. However, just as these three parameters cannot be used to judge the overall suitability of the fabrics for the end-use. It is therefore recommended that further investigations are carried out on the fabrics to evaluate other characteristics such as strength and absorbency which could help to establish the better suitability of the investigated fabrics for the end-use (uniforms).For instance, looking at the percentage fibre content of fabric brand $\mathrm{C}$, it can be observed that the polyester content is very high which can negatively influence absorbency which is an important property in the tropics for comfort in clothing. In addition, relationships exist between yarn count and weight and yarn linear density and weight of the fabrics, indicating that the weight of a fabric is not only determined by the fabric's number of yarns but also by its linear density.

Since the GS 970 (2009) did not indicatespecifications for the parameters yarn count and yarn linear density that would also help to better establish the suitability of fabrics for school uniforms, it is suggested that; the Ghana Standards Authority reviews the GS 970 (2009) to include such properties of fabrics.

\section{REFERENCES}

1. Adetuyi, A. O., \&Akinbola, O. A. (2009). Physical and mechanical properties of selected school uniforms in Akure Metropolis Nigeria. Journal of the Textile Association, January-February, 291-295.

2. Behera, B. K. (2015). Role of fabric properties in the clothing manufacturing process.Garment Manufacturing Technology, 59-80.

3. Behera, B. K. (1999). Testing and quality management. IAFL, 1, 386-402.

4. Behera, B. K., \&Hari, P. K. (2009). Woven textile structure- Theory and applications. United Kingdom: Woodhead. 
5. Chan, C. K., Jiang, X. Y., Liew, K. L., Chan, L. K., Wong, W. K., \& Lau, M. P. (2006). Evaluation of mechanical properties of uniform fabrics in garment manufacturing.Journal of Materials Processing Technology, 174, 183-189.

6. Ghana Standards Authority (2009).GS ISO 970:2009 -Textiles- specification for fabrics for shirts and uniforms.Accra, Ghana: Ghana Standards Authority.

7. Glock, R. E., \& Kunz, G. I. (2005).Apparel manufacturing: sewn product analysis (4 ${ }^{\text {th }}$ ed.). New Jersey: Pearson Prentice Hall.

8. International Organization for Standardization 139 (1973).Textiles- standard atmospheres for conditioning and testing.Switzerland: International Organization for Standardization.

9. Kadolph, J. S. (2007).Quality assurance for textiles and apparel ( $2^{\text {nd }}$ ed.). New York: Fairchild Publications.

10. Kadiadze, P. (2014). Satisfaction with school uniforms: a study of selected public senior high schools in the cape coast metropolis. Unpublished master's thesis, University of Cape Coast, Cape Coast.

11. Kantheti, P. Devi, A. S., \&Anitha, D. (2015). Features preferred by primary school children in school uniform. International Journal of Science and Research, 4 (3), 885-888.

12. Luible, C., Varheemaa, M., Magnenant-Thalmann, N., \& Meinander, H. (2007). Subjective fabric evaluation. IEEE Xplore, 17. doi10.1109/cw.2007.57.

13. Masteikaite, V., Sacevičiene, V., Apparova, A., \& Gerasimovic, T. (2013).Deformability analysis of fabrics used for school uniforms.TekstilveKonfeksiyon, 23(4), 387-392.

14. Mehta, P.V., \& Bhardwaj, K.S. (1998).Managing quality in the apparel industry India: New age international publishers Ltd.

15. Lakshmi, V. V., \&Pooja, S. L. Significance Of Colour In Professional Uniforms With Reference To Air Lines.

16. Pizzuto, J. J. (2012). Fabric science (10 ${ }^{\text {th }}$ ed.). New York: Fiarchild.

17. Saiman, M. P. B., Wahab, M. S. B., \&Wahit, M. U. B. (2014). The effect of yarn linear density on mechanical properties of plain woven kenaf reinforced unsaturated polyester composite. Applied Mechanics and Materials, 465-466, 962 - 966.

18. Tang, S., \& Stylios, G. (2006).An overview of smart technologies for clothing design and engineering.International Journal of Clothing Science and Technology, 18 (2), 108-128.

19. Teli, M. D., Khare, A. R., \& Chakrabarti, R. (2008). Dependence of yarn and fabric strength on the structural parameters. AUTEX Research Journal, 8 (3), 63-67.

20. Textile Machinery Network (2013). Several factors affect the colourfastness of textiles. Retrieved November 5, 2015, from http://textilemachine.fangzhi-jixie.com/machine 1/content/?887.html

21. Ünal, Z. B., Yildiz, E. Z., \& Özdil (2011).A study on analysis and improvement of trouser fabrics used for primary school uniforms.TekstilveKonfeksiyon. 